\title{
Interlaboratory Proficiency Testing as a Tool for Improving Performance in Laboratories Diagnosing Bovine Mastitis
}

\author{
A. Pitkälä, ${ }^{1,2}$ V. Gindonis, ${ }^{1}$ H. Wallin, ${ }^{2}$ and T. Honkanen-Buzalski ${ }^{1}$ \\ ${ }^{1}$ National Veterinary and Food Research Institute, EELA, PB 45, FIN-00581 Helsinki, Finland \\ ${ }^{2}$ National Food Agency, PB 28, FIN-00581 Helsinki, Finland
}

\begin{abstract}
The National Veterinary and Food Research Institute (Finland) and the Veterinary Laboratories Agency of the Quality Assurance Unit, Department for Environment, Food and Rural Affairs, United Kingdom (previously the Ministry of Agriculture, Fisheries and Food) organized a proficiency testing program for laboratories analyzing veterinary mastitis samples. Three test samples with lyophilized strains of common aerobic bacteria were sent to the participating laboratories 7 times between 2000 and 2003. The participants returned 98\% of the requested data. The overall performance of the laboratories varied from 63 to $93 \%$ in different testing rounds. All laboratories diagnosed Staphylococcus aureus and Escherichia coli correctly at every round. Improvement in diagnosing individual bacteria was observed for Staphylococcus epidermidis, Streptococcus dysgalactiae, Enterococcus spp. and Klebsiella spp. The overall performance of the laboratories improved with increased participation. The educational role of the program was important. Laboratories working in the veterinary field should implement a documented quality system covering all functions of the laboratory, as well as a planned quality assurance system.
\end{abstract}

(Key words: mastitis, proficiency testing, interlaboratory comparison, veterinary laboratory)

Abbreviation key: EELA = The National Veterinary and Food Research Institute, ISO = International Organization for Standardization, NFA = National Food Agency, VLA = Veterinary Laboratories Agency (UK).

\section{INTRODUCTION}

Laboratory results should be accurate and appropriate. Accurate bacteriological diagnosis of clinical samples is important in veterinary medicine and it is thus necessary to know which analytical methods are in use and to have information on the general perfor-

Received August 24, 2004.

Accepted October 12, 2004.

Corresponding author: Anna Pitkälä; e-mail: anna.pitkala@eela.fi. mance of the laboratories. In cases where there is no specific legislation on the competence or performance of laboratories, it can be considered an obligation of the national reference laboratory to ensure that the analytical work in its sphere of responsibility is carried out properly. Reference laboratories may make use of various external quality control measures aimed at improving the quality of the analytical data.

The National Veterinary and Food Research Institute (EELA) is the national reference laboratory in veterinary medicine in Finland. In 1999, it issued a decision (EELA, 1999) listing competency requirements for laboratories carrying out tests for the detection of animal diseases. The requirements were as follows: 1) analyses should be performed according to relevant veterinary and good laboratory practice; 2) laboratories must have a documented quality system, suitable premises and equipment, and trained personnel; 3) management personnel responsible for analyses of animal diseases must have an academic degree; 4) the quality system must include analytical methods, equipment, evaluation of the sample and its anamnesis, results, quality assurance measures, as well as training and supervising of the personnel; and 5) the analytical methods used must be internationally accepted standards. If such methods are not available, the methods used must be approved by EELA.

There are no requirements for a clinical veterinary laboratory examining veterinary samples to seek registration or to have its competence assessed. However, laboratories investigating bovine mastitis samples are often the same laboratories (municipal, industrial, or private) that analyze official food and water samples. Such labs must, according to the food and water legislation, be recognized by the competent authority, the National Food Agency (NFA). A prerequisite for recognition by NFA is that the laboratory is accredited to EN ISO/IEC standard 17025 [International Organization for Standardization (ISO), 2000]. The competence of the laboratory to use methods that are outside the scope of its accreditation is assessed by the NFA every $5 \mathrm{yr}$. However, this assessment does not cover veterinary samples. Of the laboratories diagnosing veterinary mastitis samples in Finland, only the reference labora- 
tory has independent certification to its method according to EN ISO/IEC standard 17025. Laboratories accredited to EN ISO/IEC standard 17025 (ISO, 2000) must have both internal and external quality assurance procedures in place to demonstrate that their analytical results are reliable.

There are guidelines but no standards accepted by an international standardization organization on the cultivation of mastitis samples or on the confirmation of results. The National Mastitis Council has published guidelines (National Mastitis Council, 1999) on laboratory diagnosis of mastitis. According to the previously mentioned decision (EELA, 1999), all laboratories diagnosing mastitis must use the method described by Honkanen-Buzalski and Seuna (1995), which does not differ essentially from the NMC protocol. Both have been widely used in mastitis prevalence studies. The transition period for fulfilling the preliminary requirements and incorporating the prescribed method into use ended in 2002.

In 2000, 48 laboratories in Finland analyzed 130,000 quarter milk samples for bovine mastitis. This figure does not include those clinical mastitis samples analyzed by veterinary practitioners. Previously, the methods used were not standardized, and external quality assurance was neither systematic nor regular. Some laboratories arranged their own small-scale comparison tests, but only EELA participated in the proficiency testing arranged by the Veterinary Laboratories Agency (VLA) of the UK Department for Environment, Food and Rural Affairs. The VLA is accredited to ISO Guide 43 (ISO, 1997), which defines internationally accepted requirements for organizing proficiency testing schemes.

The National Veterinary and Food Research Institute and VLA created an assessment program as a training exercise for laboratories diagnosing mastitis in Finland. The aim of the program was to follow up on the performance of the laboratories, harmonize the analytical methods used, and train laboratory personnel in order for them to obtain equal and reliable results.

Results on long-term follow-up studies of proficiency testing programs have been published in the areas of medical and environmental analyses, food and feed microbiology, and veterinary virology (Key et al., 1997; Tholen, 2002; Morris and Macey, 2004; World Health Organization, 2004). This paper presents the results of a proficiency testing scheme for laboratories analyzing veterinary mastitis samples from 2000 to 2003.

\section{MATERIALS AND METHODS}

\section{The Testing Program}

The program for mastitis quality assessment was open to any laboratory analyzing mastitis samples. Par- ticipation was voluntary and laboratories were charged for the samples. Seven rounds were organized from 2000 to 2003. Each round consisted of 3 test samples. The test protocol and materials were supplied by VLA. The test samples comprised lyophilized strains of common aerobic bacteria found in mastitis samples, either in pure $(\mathrm{n}=13)$ or in mixed $(\mathrm{n}=8)$ culture (Table 1). The samples were sent from VLA to EELA, which distributed them to the participating laboratories. There were 20 to 45 participants per round. Participants were asked to return the results within 3 wk. The laboratories were asked which confirmatory tests they used. A survey concerning the analytical and quality assurance methods in use was made before the first round and during the fourth round of the program.

\section{Performance Assessment of Laboratories}

The results were scored as correct (2), partially correct (1), or incorrect (0). A correct result indicated that the bacteria were correctly identified with adequate precision. Depending on the clinical need, some bacteria were to be diagnosed at the species level, e.g., Streptoccoccus agalactiae, Streptococcus uberis, and Escherichia coli; and some at the genus level, e.g., Enterococcus spp., Lactococcus spp. or Klebsiella spp. A result specifying coagulase-positive staphylococci was acceptable for Staphylococcus aureus, and one specifying CNS was acceptable for Staphylococcus epidermidis and Staphylococcus xylosus. A result was considered partially correct when the target bacterium was correctly identified but other bacteria not included in the sample were also reported. A response of Bacillus spp. for $B$. cereus, or Corynebacterium spp. for $C$. bovis was accepted as partially correct. A result was considered incorrect when identification was wrong, for example, if Arcanobacterium pyogenes was identified as Listeria monocytogenes, or Klebsiella pneumoniae was identified as $E$. coli. The result was also scored as incorrect if reported as "gram-positive cocci," or "gram-negative rod". Because the analysis in question is qualitative, no statistical analysis of the results was performed.

\section{Reporting of Results}

The report of each testing round was sent to the participating laboratories within 2 mo. The correct answers were available on EELA's web site immediately after closure of the round. The reports discussed laboratory diagnostics, information on misidentified organisms, common errors, taxonomy, and information on the medical relevance of certain bacteria. Reports also included individual performance scores on each sample for all laboratories. The results were given under each labora- 
Table 1. Bacteria included in the samples in different testing rounds.

\begin{tabular}{|c|c|c|c|c|c|c|c|}
\hline \multirow[b]{2}{*}{ Bacteria } & \multicolumn{7}{|c|}{ Testing round } \\
\hline & 1 & 2 & 3 & 4 & 5 & 6 & 7 \\
\hline Arcanobacterium pyogenes & & & $x$ & & & & \\
\hline Bacillus cereus & & & & & $x$ & & \\
\hline Corynebacterium bovis & & & $x$ & & & & \\
\hline Enterobacter aerogenes & & & & & $x$ & & \\
\hline Enterococcus faecalis & $x$ & & $x$ & $x$ & & & $x$ \\
\hline Escherichia coli & & & $x$ & & $\times$ & & \\
\hline Klebsiella pneumoniae & & $x$ & & $x$ & & & $x$ \\
\hline Lactococcus lactis & & & & & & $x$ & \\
\hline Proteus mirabilis & & $x$ & & $x$ & & & $x$ \\
\hline Serratia marcescens & & & & & & $x$ & \\
\hline Staphylococcus epidermidis & & $x$ & $x$ & & & & \\
\hline Staphylococcus aureus & $x$ & & & & & $x$ & \\
\hline Staphylococcus xylosus & & & & $x$ & & & \\
\hline Streptococcus agalactiae & $x$ & & & & & & \\
\hline Streptococcus dysgalactiae & & $x$ & & & $x$ & & $x$ \\
\hline Streptococcus uberis & & $x$ & & $x$ & & & \\
\hline
\end{tabular}

tory's unique identification number so that the participants and their results remained confidential. Laboratories with unsatisfactory results were advised to review their work routines and to take corrective actions. Laboratories with poor performance were offered repeat samples at no cost, and in some cases, additional help and training.

\section{RESULTS}

The number of participants and the overall performance of all laboratories in each round are presented in Table 2, and the results of identification of different bacteria in Figure 1. The overall performance of each laboratory is presented in Figure 2. Two laboratories left the program midway because they had ceased testing for clinical mastitis. The return rate of data from laboratories was $98 \%$. The mean cumulative score calculated from all samples was $83 \%$ from the maximum score for those laboratories that participated 6 to 7 times $(\mathrm{n}=20)$, whereas the corresponding figure was 58 to $79 \%$ for laboratories that participated less frequently ( 2 to 5 times). Three laboratories participated

Table 2. Overall performance of laboratories.

\begin{tabular}{llll}
\hline $\begin{array}{l}\text { Round } \\
\text { no. }\end{array}$ & $\begin{array}{l}\text { No. of } \\
\text { participants }\end{array}$ & $\begin{array}{l}\text { Data } \\
\text { return, } \%\end{array}$ & $\begin{array}{l}\text { Satisfactory } \\
\text { rate, } \%^{1}\end{array}$ \\
\hline 1 & 45 & 100 & 89 \\
2 & 38 & 97 & 79 \\
3 & 36 & 97 & 63 \\
4 & 37 & 95 & 83 \\
5 & 25 & 100 & 93 \\
6 & 40 & 98 & 71 \\
7 & 20 & 100 & 90 \\
\hline
\end{tabular}

${ }^{1}$ Total scores/maximum scores per round. only once and their mean cumulative score was $94 \%$. Extraneous growth not included in the target bacteria was reported by 14 laboratories in one round, by 9 laboratories in 2 rounds, and by 2 laboratories in 3 rounds.

Before the start of the training program, $45 \%$ of the laboratories used the method described by HonkanenBuzalski and Seuna (1995) and recommended by EELA, $30 \%$ used their own modification of this method, and $25 \%$ used other, unpublished methods. During the program these figures changed to 52,27 , and $21 \%$, respectively. No laboratory had accreditation for the analytical method used, although $74 \%$ of the laboratories were accredited in other areas. Mastitis analyses were fully included in the quality system in $84 \%$ of the laboratories, and partially included in $7 \%$ of the laboratories. According to the survey, $9 \%$ of the laboratories reported that mastitis analyses were not included in their quality system.

\section{DISCUSSION}

The data return rate of $98 \%$ was considered very good. Key et al. (1997) reported an overall return rate of $85 \%$ in proficiency testing in the area of food and feed analyses. The laboratories in this study were very motivated to take part in the program, and it is believed that the need to reserve budgetary funds for participation contributed to the high return rate. The overall performance of the laboratories improved with increased participation, as reported in other studies (Key et al., 1997; Augustin and Carlier, 2002). For the 3 laboratories that participated only once, their results may be misleading, because the round in question was one in which most laboratories had correct results. Conclusions drawn from single performance exercises 


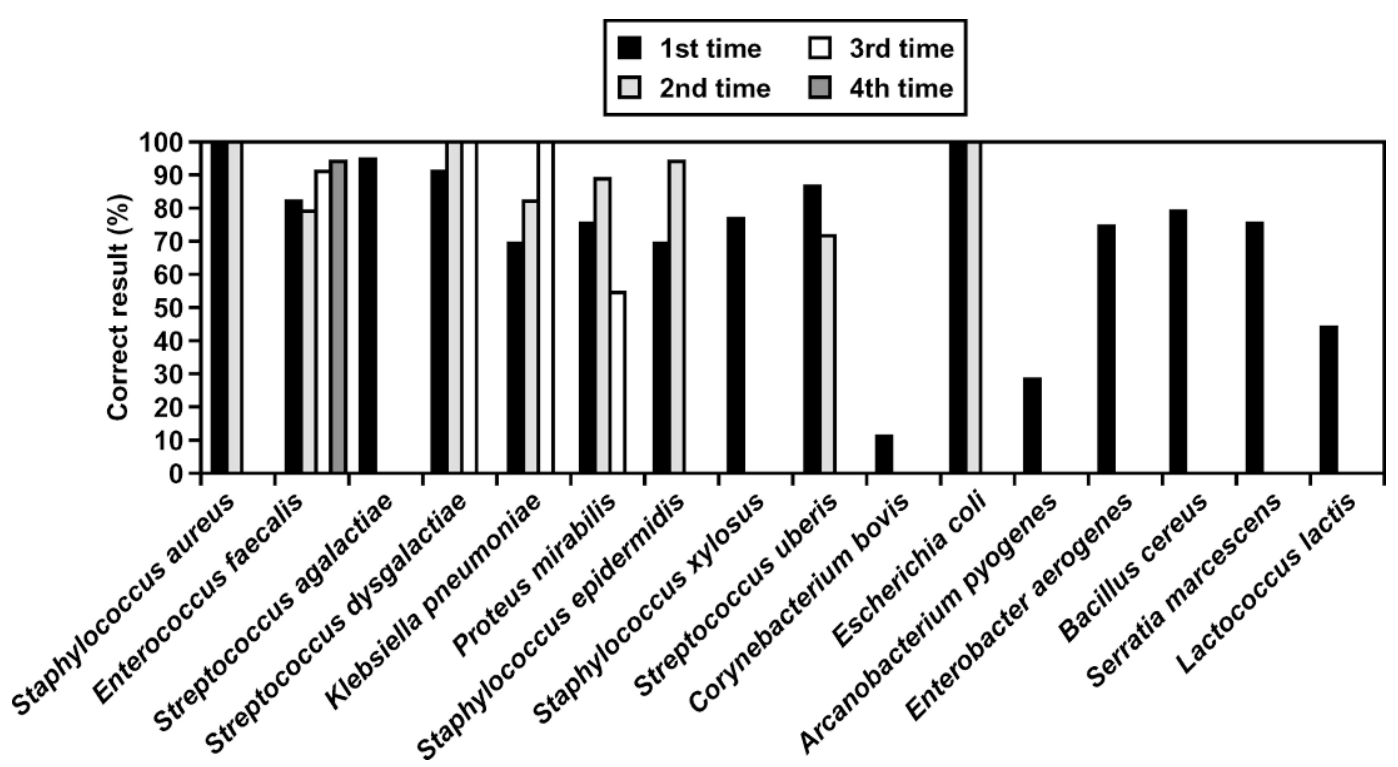

Figure 1. Correct results of different test bacteria in different test rounds, when a given organism was in the samples for the first, second, third, and fourth times.

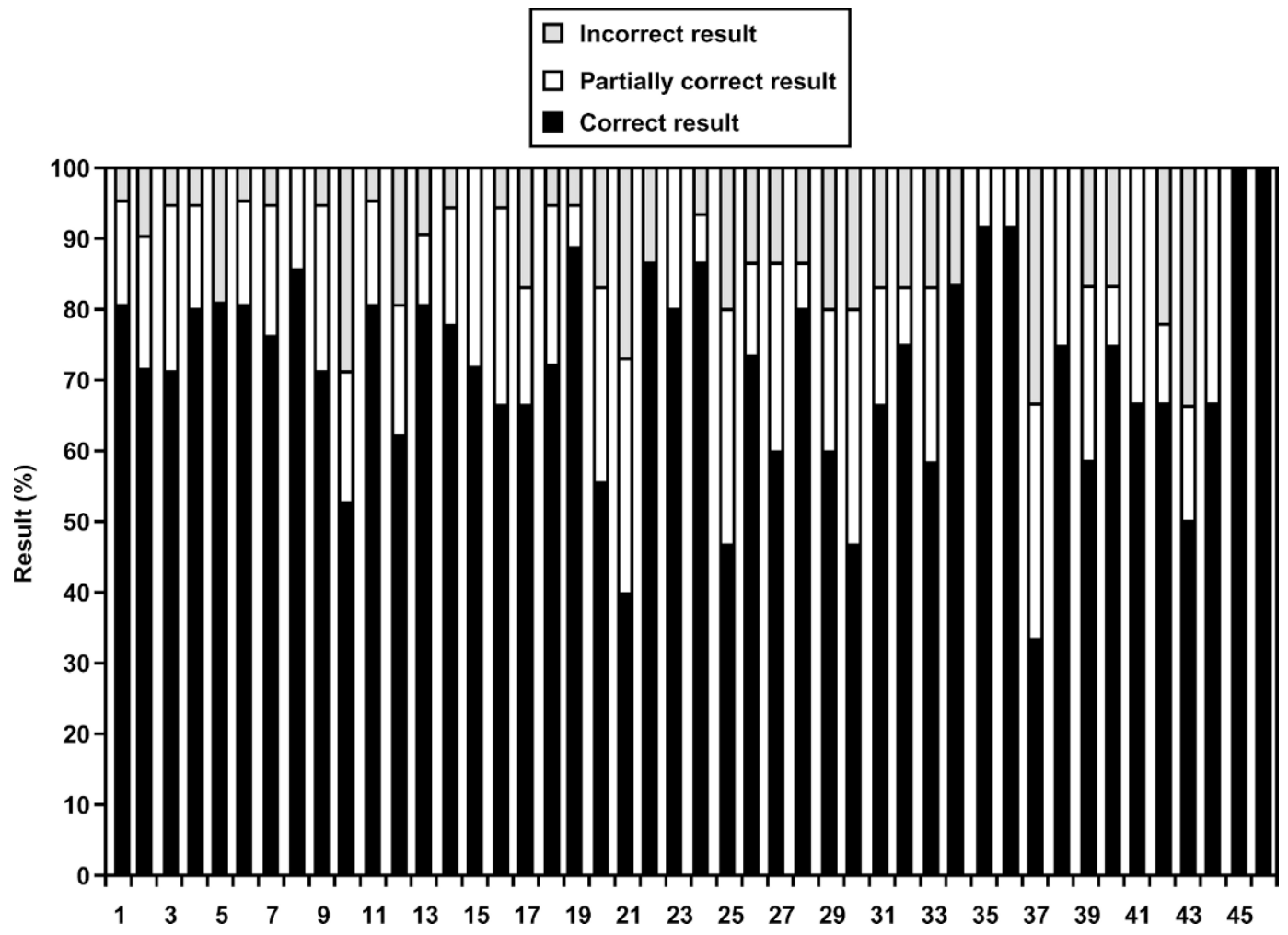

Figure 2. Mean of results (\%) per laboratory. Laboratories 1 to 13 participated 7 times, laboratories 14 to 20 participated 6 times, laboratories 21 to 30 participated 5 times, laboratories 31 to 41 participated 4 times, laboratory 42 participated 3 times, laboratory 43 participated 2 times, and laboratories 44 to 46 participated only once. 
should not be taken as representative of overall performance (Cortez et al., 2003).

Often, laboratories that are not previously acquainted with proficiency testing have higher rates of unacceptable results. In laboratories that are familiar with proficiency testing, changes in performance are expected to reflect changes in quality rather than familiarization with the program (Tholen, 2002; Morris and Macey, 2004). Laboratories participating in this program were either accredited or approved by the NFA, and thus familiar with quality assurance samples and quality assurance measures. We can assume that improvement was largely due to better performance. Laboratories reviewed procedures and corrected techniques, and some adopted the recommended methodology and confirmation tests. The recommended tests were made available to the laboratories through the EELA web site (www.eela.fi). The poor performance (especially in the third round) was an indication that there is a need for hands-on training. The veterinary faculty of the University of Helsinki and the Finnish Association for Milk Hygiene arranged, in cooperation with the reference laboratory, two 2-d courses on mastitis diagnostics after the fourth and fifth rounds for both managerial and technical laboratory personnel. Subsequently, reporting the results became more uniform, and there was improvement in understanding the diversity of organisms causing mastitis as well as in the performance of the tests. The overall improvement was quite rapid, which reflects the fact that the laboratories were motivated to change their procedures and used the program as a source of relevant training. We consider that the reports issued after each round were an essential element, and that the educational role of the proficiency testing itself is important. Tholen (2002) also noted the importance of the educational role of proficiency testing.

Extrapolation from success in proficiency testing schemes to proficiency in everyday analytical work is an assumption. Although proficiency test samples should be handled in a routine manner, laboratories may, for example, put extra effort or choose the best staff for the analysis. Laboratories may exchange information or use subcontracting (Wood et al., 1998). The results from a proficiency testing scheme may be regarded as an indication of whether a laboratory, at its best, is able to perform a given analytical test and not necessarily whether their daily performance is adequate (Cortez et al., 2003).

All laboratories diagnosed Staph. aureus and E. coli correctly in every round of testing. Improvement in the diagnosis of other bacteria was observed for Staph. epidermidis, Strep. dysgalactiae, Enterococcus spp. and Klebsiella spp. (Figure 1). The results for Arcanobacterium pyogenes and Proteus spp. show the importance of reading the cultivated plates after $48 \mathrm{~h}$; slower-growing bacteria may go unnoticed under faster-growing bacteria. Regarding the slow-growing $C$. bovis, the poor performance in this study was due to misidentification due to lacking or improper confirmation. Problems of identification of $C$. bovis were also reported by Watts et al. (2000). Identification of species that appeared only once or twice in the samples was an important educational aspect of the program, and the possible improvements in this area will be verified in future proficiency testing.

Staphylococcus epidermidis and Staph. xylosus are both considered CNS. The results for CNS samples generally varied. Only $70 \%$ of the results were correct when CNS (Staph. epidermidis) was identified for the first time, $94 \%$ of the results were correct the second time (Staph. epidermidis), and 77\% were correct when CNS (Staph. xylosus) was identified for the third time. This may be because some rapid tests used for testing coagulase production gave false positive results with Staph. xylosus.

The changes in bacterial taxonomy were not well known in the laboratories. This was particularly true in the case of the genus Enterococcus, which was diagnosed as Streptococcus. Laboratory results guide veterinarians in selection of the most prudent antibiotic therapy for mastitis, and errors of this type can lead to an inappropriate choice of antimicrobial therapy (Rossitto et al., 2002). Especially at the beginning of the program, confirmation of the identity of the bacteria was missing in some laboratories, and the variety of confirmatory tests used was considerable. Furthermore, some laboratories used confirmatory tests originally developed for bacteria of human origin. Discrepancy in the results may occur when using these for testing bacteria encountered in clinical veterinary samples (Watts and Yancey, 1994; Devriese et al., 1999).

One problem with using samples of lyophilized strains may be that they might require multiple passages to reactivate characterizing enzymes and typical colony morphology (Noble, 2002). This phenomenon was not considered as a disadvantage, because strains also show variation in true mastitis samples. In our own studies, $23 \%$ of Klebsiella spp. strains and $12 \%$ of Strep. uberis strains isolated from clinical and subclinical mastitis samples have been atypical (Pitkälä and Pyörälä, 2003).

The technical handling of ampoules may have caused cross-contamination of the samples in the laboratory, because the number of laboratories reporting extraneous bacterial growth was relatively high. The type of additional growth in a sample was usually a strain from another sample. Laboratories were advised to pay 
attention to aseptic handling, and only 2 laboratories had cross-contamination on more than 2 occasions.

None of the laboratories sought accreditation for the method during the program. The absence of quality assurance measures for fertility, sterility, $\mathrm{pH}$ checks of the media, use of control strains, and calibration and performance checks of equipment in some laboratories was worrying. It is essential that laboratories understand that even in the absence of official requirements in the legislation, important elements of reliable microbiological analysis should not be overlooked. In many laboratory sectors there is either a voluntary or a mandatory tendency toward accreditation to internationally accepted standards. The veterinary laboratory field should follow this development, and determine the level of quality assurance that should be in place, and the level and type of recognition that veterinary laboratories need (Wiegers, 2002).

The laboratories in the field are usually small, with an average of less than 10 persons working with microbiological samples, often with 2 to 4 of them analyzing mastitis samples, one technical and one managerial person at a time. The situation does not differ much from laboratory to laboratory. Our conclusion is that laboratory staff size did not affect the results. When the number of samples handled per year exceeded 3000 , the results were more reliable and of uniform quality. One important reason for poor diagnostics was economic. Because of competition, laboratories try to reduce the cost of analysis, and provide results to the client as quickly as possible. For this reason, confirmatory tests were not performed properly in all laboratories. The combination of low cost and inadequate diagnosis is a poor service to the client, who is not an expert in interpreting whether the laboratory information is appropriate to improve the health of his or her animals. A laboratory investigating clinical samples must have medical competence to make diagnoses at levels adequate for animal health care and legal protection of the client. The proper bacteriological diagnosis is also important to ensure prudent use of antimicrobials and limit resistance development, as the majority of antimicrobial products in dairy farming are used for the treatment of mastitis. It can only be hoped that the use of cheap and inadequate diagnostics is not undermining those laboratories that give priority to the quality of their services. In the future market only those service providers who offer optimal quality at acceptable prices will be successful (Vogt, 2001).

Some form of laboratory assessment system corresponding to those that already exist in food and water analysis should be implemented in the veterinary laboratory field. The general benefits of accreditation include increased productivity, improved performance, increased morale of staff, recognition and acceptance of competence, and increased ability to stay abreast of developments in requirements for competence and testing (Wiegers, 2002). Although accreditation alone cannot guarantee the quality of the data produced by the laboratory, it should decrease the frequency of incorrect results (Cortez et al., 2003). Requiring accreditation may be too stringent in an area such as this, in which accreditation services are not well developed. As a first measure, it is important that veterinary diagnosis is carried out by competent personnel using relevant and validated methods of analysis. The laboratories should have a documented quality control system covering all functions of the laboratory, a planned external and internal quality assurance system, and methods that function well.

The laboratories that participated in this training program were advised to participate in proficiency testing programs arranged by VLA, and this began in 2004 . Our experience from this program is that it is important for national reference laboratories to follow up on the performance and implementation of corrective actions.

\section{ACKNOWLEDGMENTS}

The authors are grateful to VLA for cooperation in the program.

\section{REFERENCES}

Augustin, J.-C., and V. Carlier. 2002. French laboratory proficiency testing program for food microbiology. J. AOAC 85:952-959.

Cortez, L., A. Duarte, A. Hundewadt, A. Schmidt, B. Steffen, D. Tholen, H. Fostel, I. Papadakis, M. G. del Monte, N. Boley, and P. M. van Berkel. 2003. How to interpret information from proficiency test exercises concerning the relative performance of accredited laboratories. Accred. Qual. Assur. 8:511-513.

Devriese, L. A., J. Hommez, H. Laevens, B. Pot, P. Vandamme, and F. Haesebrouck. 1999. Identification of aesculin-hydrolyzing streptococci, lactococci, aerococci, and enterococci from subclinical intramammary infections in dairy cows. Vet. Microbiol. 70:87-94.

EELA. 1999. Eläintautitutkimuksia tekevien laboratorioiden pätevyysvaatimukset. Eläinlääkintä- ja elintarvikelaitoksen päätös 697/3/99. Online. Available http://www.mmm.fi/el/laki/d/d10. html. Accessed Nov. 25, 2004.

Honkanen-Buzalski, T., and E. Seuna. 1995. Isolation and identification of pathogens from milk. Pages 121-141 in The Bovine Udder and Mastitis. M. Sandholm, T. Honkanen-Buzalski, L. Kaartinen, and S. Pyörälä, ed. Gummerus Press, Jyväskylä, Finland.

International Organization for Standardization (ISO). ISO Guide 431. 1997. Proficiency testing by interlaboratory comparisons. Part 1: Development and operation of proficiency testing schemes. ISO/ IEC, Geneva, Switzerland.

International Organization for Standardization (ISO). 2000. General requirements for the competence of testing and calibration laboratories (EN ISO/IEC 17025:1999). CEN/CENELEC, Brussels, Belgium.

Key, P. E., A. L. Patey, S. Rowling, A. Wilbourn, and F. M. Worner. 1997. International proficiency testing of analytical laboratories for foods and feeds from 1990 to 1996: The experiences of the United Kingdom food analysis performance assessment scheme. J. AOAC 80:895-899. 
Morris, A., and D. Macey. 2004. Laboratory accreditation: Proof of performance for environmental laboratories - 2001 study. Accred. Qual. Assur. 9:52-54.

National Mastitis Council. 1999. Laboratory Handbook on Bovine Mastitis. Natl. Mastitis Counc. Inc, Madison, WI.

Noble, M. A. 2002. Advances on microbiology EQA. Accred. Qual. Assur. 7:341-344.

Pitkälä, A., and S. Pyörälä. 2003. Laboratory and mastitis. Suom. Ellääk. Lehti. 11:593-597.

Rossitto, P. V., L. Ruiz, Y. Kikuchi, K. Glenn, K. Luiz, J. L. Watts, and J. S. Cullor. 2002. Antibiotic susceptibility patterns for environmental Streptococci isolated from bovine mastitis in Central California dairies. J. Dairy Sci. 85:132-138.

Tholen, D. W. 2002. Improvements in performance in medical diagnostics tests documented by interlaboratory comparison programs. Accred. Qual. Assur. 7:146-152.

Vogt, W. 2001. The German perspective of using the EFQM model in medical laboratories. Accred. Qual. Assur. 6:396-401.
Watts, J. L., and R. J. Yancey. 1994. Identification of veterinary pathogens by use of commercial identification systems and new trends in antimicrobial susceptibility testing of veterinary pathogens. Clin. Microbiol. Rev. 7:346-356.

Watts, J. L., D. E. Lowery, J. F. Teel, and S. Rossbach. 2000. Identification of Corynebacterium bovis and other Coryneforms isolated from bovine mammary glands. J. Dairy Sci. 83:2373-2379.

Wiegers, A. 2002. The age of competence: An update on the international laboratory accreditation scene for veterinary testing laboratories. J. Vet. Diagn. Invest. 14:89-96.

Wood, R., A. Nilsson, and H. Wallin. 1998. Role of proficiency testing in the assessment of laboratory quality. Pages 172-202 in Quality in the Food Analysis Laboratory. The Royal Society of Chemistry, Cambridge, UK.

World Health Organization (WHO). 2004. Online. Available www.who.int/salmsurv/activities/GSS_EQAS/ GSSequas2002page/en/print.html. Accessed Aug. 12, 2004. 